\section{Chloroquine resistant Plasmodium falciparum malaria in Zimbabwe}

Resistance of Plasmodium falciparum to chloroquine in Africa was first reported from Kenya in 1979. ${ }^{1}$ Since then reports of resistant strains from other parts of Africa have continued to appear. Drug sensitivity studies during the 1983 and 1984 malaria seasons in endemic areas in the north east and south east of Zimbabwe showed that $P$ falciparum infections in these localities were fully sensitive to a standard course of chloroquine. ${ }^{2}$ We report the first seven cases of confirmed chloroquine resistant $P$ falciparum infection acquired in the Zambezi Valley of Zimbabwe.

\section{Patients, methods, and results}

Four of the seven patients (cases 1-4) were treated for malaria between May and September 1984 as inpatients or outpatients in various Harare hospitals. They work transfer from Harare, an area hypoendemic for malaria, and were taking chloroquine as prophylaxis before the onset of their illness. All four patients failed to respond to at least the initial two standard courses of chloroquine and were referred for chloroquine sensitivity tests. The remaining three patients were resident in the Zambezi Valley, an area hyperendemic for malaria, and had asymptomatic $P$ falciparum infections confirmed during routine drug sensitivity tests conducted in Kanyemba in August 1984

Blood samples from seven patients were subjected to the in vitro macro test for chloroquine resistant $P$ falciparum malaria. ${ }^{3}$ Before in vitro testing, all the patients underwent the Dill-Glazko test for chloroquine in urine. ${ }^{4}$ Schizont maturation was expressed in relation to 300 leucocytes.

Blood smears from all seven patients before the in vitro tests disclosed parasitaemias ranging from $3020 \times 10^{6}$ to $21040 \times 10^{6}$ parasites per litre of blood, and this was considered suitable for in vitro studies (table). One patient (case 1) failed to respond to a single dose of $1500 \mathrm{mg}$ sulfadoxine and $75 \mathrm{mg}$ pyrimethamine (three tablets of Fansidar) and was finally cured with $4.5 \mathrm{~g}$ oral quinine and $5.25 \mathrm{~g}$ tetracycline administered concurrently over three and seven days, respectively. A single dose of Fansidar cured two patients (cases 2 and 3). Case 4 responded to a third course of chloroquine $(1.8 \mathrm{~g}$ base parenterally) given five days after a course of sulphadimidine for a urinary tract infection.

\section{Comment}

Persistence of schizont maturation at chloroquine concentrations greater than $1.0 \mu \mathrm{mol} / \mathrm{l}(32.0 \mu \mathrm{g} / 100 \mathrm{ml})$ blood show that $P$ falciparum isolates in the Zambezi Valley are resistant to a standard course of chloroquine, which agrees with the patients' failure to respond to the initial standard or multiple courses of chloroquine. In view of resistance already reported in parasites isolated from Zambia, ${ }^{5}$ which verbal reports now give as being widespread, and the absence of mass chloroquine distribution in the Zambezi Valley of Zimbabwe, probably the resistant parasites reported here had spread into Zimbabwe from neighbouring Zambia in the north. The extent of chloroquine resistant malaria in the Zambezi Valley of Zimbabwe is unknown, and more surveillance of drug sensitivity must therefore be undertaken to obtain information on the changing pattern of sensitivity of $P$ falciparum to chloroquine.

Fansidar, quinine, and tetracycline should be reserved for cases of chloroquine resistant infections. Chloroquine, however, remains the drug of choice for sensitive $P$ falciparum infections by virtue of its efficacy, low cost, and ready availability. The use of chloroquine as prophylaxis had been in the Zambezi Valley (either Kanyemba or Chirundu) on holiday or

should be under strict control throughout Zimbabwe so as to reduce drug selection pressure on $P$ falciparum. Alternative agents such as a combination of pyrimethamine $(12.5 \mathrm{mg})$ and dapsone $(100 \mathrm{mg})$ should be used, though recommendations about appropriate prophylaxis must take many factors into account.

1 Fogh S, Jepson S, Efferse P. Chloroquine-resistant Plasmodium falciparum in Kenya. Trans $R$ So Trop Med Hyg 1979;73:228-9.

2 Mutambu SL. Drug resistance of Plasmodium falciparum in Africa with particular reference to chloroquine resistance in Zimbabwe. Cent Afr f Med 1984;30:269-72.

3 Rieckmann KH, Antunano L. Chloroquine resistance of Plasmodium falciparum in Brazil detected by a simple in vitro method. Bull WHO 1971;45:157-67.

4 Lelijveld J, Kortmann H. The eosin colour test of Dill and Glazko: a simple field test to detc chloroqquine in urine. Bull WHO 1970;42:477-9.

5 Kofie-Ekue JN, Ulrick A, Njelesani EK. Plasmodium malaria resistant to chloroquine in a Zambian living in Zambia. Br Med f 1983;286:1315-6.

(Accepted 12 September 1985)

Blair Research Laboratory, PO Box 8105, Causeway, Harare, Zimbabwe

$S$ L MUTAMBU, BsC, medical research officer, Ministry of Health

A B C DALLAS, MB, PHD, government medical officer

University of Zimbabwe, Harare, Zimbabwe

C L M OLWENY, MD, WHO visiting professor of medicine

Correspondence to: Miss Mutambu.

\section{The provenance of extradural haematomas}

Extradural haematoma is a lethal, if uncommon, complication of minor head injury. Fear of its generation causes the admission to hospitals in England and Wales of about one quarter of a million patients each year. In 1982 in the northern part of the South Western region 4743 patients were admitted with head injury alone, 4343 for fewer than seven days. Nine cases of extradural haematoma were diagnosed, an incidence of less than $0.2 \%$ of those admitted, although an unknown number may have died on the way to hospital.

Guidelines for the management of head injury have been published by a group of neurosurgeons based on observed indicants of extradura haematoma and aimed at reducing unnecessary admissions with more effective care of those whose brain injury demands close attention. ${ }^{1}$ We have assessed these in a retrospective study.

\section{Methods and results}

The records of 100 consecutive cases of extradural haematoma admitted to the neurosurgical unit at Frenchay Hospital, Bristol, over 10 years (1974-84) were analysed to test the strength of the guidelines.

Of the 100 patients, 32 were aged under 12,18 were teenagers, and 65 were under 30 . Some 52 had been in road traffic accidents, 16 having fallen from a bicycle; 23 cases had arisen from accidents at home and 13 from sport. Only three had been caused by assault, and in only five was alcohol a complication. One third (32) had presented to the district hospital for the first time with their extradural

Results of in vitro macro tets for sensitivity of $\mathrm{P}$ falciparum to chloroquine, Zambezi Valley, Zimbabwe

\begin{tabular}{|c|c|c|c|c|c|c|c|c|c|c|c|c|c|c|}
\hline \multirow[b]{3}{*}{ Case No } & \multirow[b]{3}{*}{ Age and sex } & \multirow{3}{*}{$\begin{array}{c}\text { Preculture } \\
\text { asexual parasite } \\
\text { count in blood } \\
\left(\times 10^{6} / 1\right)\end{array}$} & \multicolumn{11}{|c|}{ Schizonts per 300 leucocytes } & \multirow{3}{*}{$\begin{array}{c}\text { Result of } \\
\text { Dill-Glazko test } \\
\text { before in vitro tests }\end{array}$} \\
\hline & & & \multicolumn{2}{|c|}{ Control } & \multirow[b]{2}{*}{ Mean } & \multicolumn{8}{|c|}{ Chloroquine concentrations ( $\mu \mathrm{mol} / / \mathrm{blood}$ ) } & \\
\hline & & & 1 & 2 & & $0 \cdot 25$ & 0.50 & $0 \cdot 75$ & $1 \cdot 00$ & $1 \cdot 25$ & $1 \cdot 50$ & $2 \cdot 00$ & 3.00 & \\
\hline 1 & $25 \mathrm{M}$ & 3020 & 24 & 30 & 27 & 17 & 17 & 14 & 13 & 10 & 9 & 14 & 7 & + \\
\hline 2 & $30 \mathrm{~F}$ & 21040 & 14 & 14 & 14 & 14 & 10 & 8 & 5 & 7 & 6 & 7 & 6 & + \\
\hline 3 & $29 \mathrm{~F}$ & 16000 & 42 & 32 & 37 & 26 & 30 & 18 & 12 & 5 & 11 & 7 & 7 & + \\
\hline 4 & $45 \mathrm{M}$ & 17307 & 28 & 22 & 25 & 22 & 14 & 10 & 8 & 10 & 8 & 5 & 6 & + \\
\hline 5 & $10 \mathrm{~F}$ & 11160 & 13 & 13 & 13 & 8 & 7 & 9 & 4 & 5 & 3 & 8 & 6 & - \\
\hline 6 & $15 \mathrm{~F}$ & 11813 & 52 & 42 & 47 & 28 & 30 & 22 & 31 & 20 & 34 & 20 & 26 & - \\
\hline 7 & $14 \mathrm{~F}$ & 7013 & 17 & 23 & 20 & 15 & 18 & 12 & 11 & 9 & 13 & 8 & 8 & - \\
\hline Mean parasi & & 12479 & 27 & 25 & 26 & 19 & 18 & 13 & 12 & 9 & 12 & 10 & 9 & \\
\hline
\end{tabular}

Conversion: SI to traditional units - Chloroquine: $1 \mu \mathrm{mol} / 1 \approx 32 \cdot 0 \mu \mathrm{g} / 100 \mathrm{ml}$ 